\title{
AVALIAÇÃO DA SUPLEMENTAÇÃO DE MACRO E MICRONUTRIENTES NO TRATAMENTO DE EFLUENTE DA PRODUÇÃO DE BIODIESEL
}

\author{
P. B. A. BEDOR ${ }^{1}$, J. V. R. CRUZ ${ }^{2}$, L. YOKOYAMA ${ }^{3}$ e M. C. CAMMAROTA ${ }^{4}$ \\ 1,2 Universidade Federal do Rio de Janeiro, Escola de Química \\ ${ }^{3}$ Universidade Federal do Rio de Janeiro, Escola de Química, Departamento de Processos Inorgânicos \\ ${ }^{4}$ Universidade Federal do Rio de Janeiro, Escola de Química, Departamento de Engenharia \\ Bioquímica \\ E-mail para contato: priscillabedor@eq.ufrj.br
}

\begin{abstract}
RESUMO - O aumento da porcentagem de biodiesel na mistura com o diesel convencional resultou no aumento da produção de biodiesel e consequentemente dos efluentes gerados no processo. Visando ao enquadramento aos padrões de descarte e à produção de energia na forma de metano, que pode ser aproveitada na própria indústria produtora de biodiesel, o tratamento biológico anaeróbio foi avaliado após um tratamento físico-químico (coagulação/flotação e flotação), necessário para remoção de óleos e graxas e material coloidal. Diferentes condições de suplementação foram avaliadas na etapa biológica, sendo a suplementação com 2,8 g/L NH${ }_{4} \mathrm{Cl}, 0,6 \mathrm{~g} / \mathrm{L} \mathrm{KH}_{2} \mathrm{PO}_{4}$ e 1,0 mL/L micronutrientes a que apresentou maior remoção de demanda química de oxigênio - DQO (98\%) e produção específica de metano (268,8 $\mathrm{mL} \mathrm{CH}_{4} / \mathrm{g}$ DQO removida). Esta condição foi selecionada para a operação de reator anaeróbio de manta de lodo e fluxo ascendente (UASB).
\end{abstract}

\section{INTRODUÇÃO}

O Brasil apresenta grande potencial para a produção de biodiesel. Isto de deve à sua extensa área geográfica e clima tropical e subtropical, o que favorece uma ampla diversidade de matériasprimas para a produção deste biocombustível (SEBRAE, 2007).

A introdução do biodiesel na matriz energética brasileira é de relevante importância ambiental, social e econômica, configurando também no Brasil como um marco histórico de investimentos em energias mais limpas, tais como o álcool e as hidrelétricas (SEBRAE, 2007).

A Agência Nacional do Petróleo, Gás Natural e Biocombustíveis (ANP) aponta, em seu sítio eletrônico, as vantagens do uso de biocombustíveis. Entre elas a menor poluição por uma menor emissão de compostos quando comparado aos combustíveis fósseis no processo de combustão dos motores e também porque seu processo de produção tende a ser mais limpo.

A Resolução nº 6/2009 do Conselho Nacional de Política Energética (CNPE), publicada em $1^{\circ}$ 


\section{9 a 22 de outubro de 2014 \\ Florianópolis/SC}

de janeiro de 2010, determina que o óleo diesel comercializado em todo o Brasil contenha 5\% de biodiesel. Esta regra aumentou de $4 \%$ para $5 \%$ o percentual obrigatório de mistura de biodiesel ao óleo diesel.

A grande produção de biodiesel acarreta uma maior produção de efluente nas indústrias produtoras deste biocombustível. Com a maior produção, o tratamento desses torna-se essencial para que o efluente tratado tenha qualidade para descarte nos corpos d’água ou reuso como água de lavagem do biodiesel.

Na produção de biodiesel, óleo vegetal e gordura animal são submetidos a uma reação química, denominada transesterificação, que consiste na reação entre um triglicerídeo e um álcool de cadeia curta, na presença de um catalisador, geralmente alcalino (Dabdoub et al., 2009).

Após esta reação, o glicerol é separado dos ésteres metílicos por decantação. No entanto, visando atender aos critérios de qualidade do biodiesel, previstos na Resolução ANP 07/2008, é necessária uma etapa de purificação para remover qualquer resíduo que tenha ficado no biodiesel, sendo a lavagem aquosa a técnica utilizada atualmente (Meneses et al., 2012).

A referida etapa de lavagem é repetida de duas a cinco vezes dependendo da quantidade de impurezas, sendo estas relacionadas a resíduos de glicerina, ácidos graxos e sabões. Após a etapa de purificação, o efluente é composto, em suma, por resíduos de sabões de sódio e potássio, além de ácidos graxos, glicerina, álcool (metanol ou etanol), dentre outros contaminantes (Palomino-Romero et al., 2012).

Em geral, o efluente proveniente da indústria de biodiesel mostra-se quimicamente inadequado para ser lançado em qualquer corpo hídrico. Sendo necessária, para isso, a adoção do tratamento destas águas residuárias, como a remoção preliminar de óleos e graxas e matéria suspensa por processos de flotação por ar dissolvido (FAD) com posterior coagulação/floculação com cloreto férrico, antes do tratamento biológico (Araújo, 2011).

Experimentos conduzidos por Suehara et al. (2005) demonstraram que quanto maior a concentração de sólidos presentes no efluente, menor é a taxa de crescimento específica máxima do micro-organismo. Portanto, uma remoção preliminar de óleos e graxas e matéria suspensa se faz necessária antes do tratamento biológico.

Ainda assim, após o tratamento por FAD seguido de coagulação/floculação com diferentes coagulantes, os valores de DQO ainda permanecem bastante elevados (em torno de $6000 \mathrm{mg} / \mathrm{L}$ ) sendo necessário um tratamento biológico para reduzi-los (Araújo, 2011).

O tratamento biológico, após as etapas de tratamento físico-químico, permitirá a obtenção de um efluente tratado que atenda aos parâmetros de descarte estabelecidos na legislação ou parâmetros de qualidade suficientes para permitir seu reuso como água de lavagem do biodiesel após tratamentos físico-químicos para polimento do mesmo.

O objetivo deste trabalho foi avaliar a aplicação do tratamento biológico anaeróbio no 
tratamento do efluente da produção de biodiesel após tratamento físico-químico. Diferentes condições de suplementação de macro e micronutrientes foram avaliadas na etapa de digestão anaeróbia, considerando maiores valores de remoção de demanda química de oxigênio (DQO) e produção específica de metano, para posterior aplicação em reator anaeróbio de manta de lodo e fluxo ascendente (UASB).

\section{METODOLOGIA}

\subsection{Caracterização do efluente}

Amostras do efluente coletado após o separador água /óleo (SAO) da planta de tratamento de uma usina de produção de biodiesel foram coletadas, submetidas a tratamento físico-químico e caracterizadas empregando-se metodologias padrão (APHA, 2005).

\subsection{Ensaios de biodegradabilidade anaeróbia}

Visando a avaliação da melhor condição de suplementação na produção de metano, foram realizados experimentos em respirômetro BIOPROCESS CONTROL AMPTS II. Os testes foram conduzidos em frascos de vidro com $400 \mathrm{~mL}$ de misturas de lodo anaeróbio (proveniente de reator UASB - upflow anaerobic sludge blanket em operação em indústria de abate de aves, com $\mathrm{SVT}=26130 \mathrm{mg} / \mathrm{L})$ e efluente diluído $(\mathrm{DQO}=3000 \mathrm{mg} / \mathrm{L})$ para uma relação DQO:SVS inicial de $1: 1$.

A caracterização do efluente após tratamento físico-químico indicou elevada deficiência de nitrogênio e fósforo (relação DQO: $\mathrm{N}$ : $\mathrm{P}=150.727$ : 10,5: 0,8), tendo-se avaliado a suplementação do meio com nitrogênio $\left(\mathrm{NH}_{4} \mathrm{Cl}\right.$ ou uréia) e fósforo $\left(\mathrm{KH}_{2} \mathrm{PO}_{4}\right)$ para uma relação ideal DQO: $\mathrm{N}: \mathrm{P}=350: 5: 1$. Avaliou-se também a suplementação com soluções de macro e micronutrientes propostas por Chernicharo (2007). O volume de solução de micronutrientes adicionado foi calculado com base na proporção das soluções de macro e micronutrientes propostas por Chernicharo ( $1 \mathrm{~mL}$ da solução micro/L da solução macro). A mistura efluente e lodo foi suplementada conforme condições 1 a 5 apresentadas na Tabela 1.

Tabela 1. Condições de suplementação avaliadas.

\begin{tabular}{cc}
\hline Condição & Suplementação \\
\hline 1 (Controle) & Sem \\
2 & Uréia $+\mathrm{KH}_{2} \mathrm{PO}_{4}$ \\
3 & $\mathrm{NH}_{4} \mathrm{Cl}+\mathrm{KH}_{2} \mathrm{PO}_{4}$ \\
4 & Uréia $+\mathrm{KH}_{2} \mathrm{PO}_{4}+$ Sol. de micronutrientes \\
5 & $\mathrm{NH}_{4} \mathrm{Cl}+\mathrm{KH}_{2} \mathrm{PO}_{4}+$ Sol. de micronutrientes \\
6 & Sol. de macronutrientes + Sol. de micronutrientes \\
\hline
\end{tabular}




\section{9 a 22 de outubro de 2014 \\ Florianópolis/SC}

$\mathrm{O}$ pH do meio foi ajustado para 7,0 com adição de bicarbonato de sódio, antes da mistura com o lodo. Os frascos foram imersos em banho com temperatura controlada a $30^{\circ} \mathrm{C}$ e agitação intermitente por agitadores rotacionais automáticos. O biogás, produzido continuamente, era conduzido, por vias individuais, a frascos que continham solução alcalina que absorvia os gases ácidos $\left(\mathrm{CO}_{2}\right.$ e $\left.\mathrm{H}_{2} \mathrm{~S}\right)$, só permitindo a passagem do metano pela unidade de monitoramento de produção de biogás em condições normais de temperatura e pressão (CNTP).

Cada condição de suplementação (Tabela 1) foi avaliada em três a cinco réplicas, sendo a biodegradabilidade avaliada através da medida de eficiência de remoção de DQO e produção específica de metano (PEM). Alíquotas para determinação da DQO inicial foram tomadas antes do contato com o lodo anaeróbio. A DQO solúvel final (obtida através da filtração do meio sobrenadante em membrana de celulose com tamanho de poro de $0,45 \mu \mathrm{m}$ ) foi determinada no último dia do ensaio, após coleta do biogás para análise por cromatografia gasosa.

Um experimento foi realizado com DQO inicial em torno de $3000 \mathrm{mg} / \mathrm{L}$ e lodo não adaptado, em 3 réplicas, nas condições 1 a 6 . Um segundo experimento foi realizado com DQO inicial em torno de $12000 \mathrm{mg} / \mathrm{L}$ a fim de avaliar o efeito da suplementação sob uma maior concentração de substrato e da adaptação do lodo. Foram avaliadas triplicatas das condições 1 e 5 com lodo não adaptado e adaptado (do experimento anterior).

\section{RESULTADOS E DISCUSSÃO}

Os resultados de caracterização do efluente após o tratamento físico-químico são apresentados na Tabela 2. Apesar de o tratamento físico-químico reduzir a concentração de óleos e graxas, a DQO permanece elevada no efluente. Tal resultado se deve à DQO encontrar-se predominantemente na forma solúvel (96\% no efluente após tratamento físico-químico), fração não removida no tratamento físico-químico.

O tratamento físico-químico não contribui para uma maior fração de matéria orgânica biodegradável no efluente, pois esta é de $25 \%$ após o pré-tratamento. Considerando que o método de determinação da demanda bioquímica de oxigênio $\left(\mathrm{DBO}_{5}\right)$ emprega micro-organismos não adaptados aos constituintes do efluente, pode-se inferir que apesar da baixa relação $\mathrm{DBO}_{5} / \mathrm{DQO}(0,25)$ o efluente após o tratamento físico-químico deve apresentar melhores resultados nos ensaios de biodegradabilidade mediante uma gradual adaptação.

As baixas concentrações de ácidos graxos voláteis (AGV) e nitrogênio amoniacal indicam que o efluente apresenta-se pouco deteriorado, provavelmente em decorrência dos baixos valores de $\mathrm{pH}$, que inibem a ação de micro-organismos. Os níveis de nitrogênio e fósforo são baixos e apontam para a necessidade de suplementação destes macronutrientes no tratamento biológico. 
Tabela 2. Caracterização do efluente da indústria de biodiesel após tratamento físico-químico.

\begin{tabular}{lc}
\hline Parâmetro & Valor \\
\hline pH & 3,65 \\
DQO total & 150.727 \\
DQO solúvel & 145.048 \\
$\mathrm{DBO}_{5}$ & 36.320 \\
Sólidos Totais & 35.767 \\
Sólidos Totais Voláteis & 24.333 \\
Sólidos Totais Fixos & 11.434 \\
Sólidos sedimentáveis & $<1$ \\
Turbidez & 21 \\
Óleos e Graxas & 23 \\
Ácidos graxos voláteis & 344,7 \\
Cloretos & 7.098 \\
Sódio & 5.000 \\
o-fosfatos & 2,35 \\
Nitrogênio total & 10,52 \\
Nitrogênio amoniacal & 2,6 \\
\hline
\end{tabular}

Todos os valores em $\mathrm{mg} / \mathrm{L}$, exceto $\mathrm{pH}$, Sólidos Sedimentáveis $(\mathrm{mL} / \mathrm{L})$ e turbidez (FTU). $\mathrm{DQO}=$ demanda química de oxigênio; $\mathrm{DBO}_{5}=$ demanda bioquímica de oxigênio em 5 dias $/ 20^{\circ} \mathrm{C}$.

A produção de metano nos ensaios de biodegradabilidade com efluente diluído para uma DQO inicial de $3000 \mathrm{mg} / \mathrm{L}$ foi monitorada até 12 dias, sendo os resultados obtidos apresentados na Tabela 3. $\mathrm{O}$ pH final se encontra próximo da neutralidade, indicando que a biodegradação atingiu a etapa metanogênica ou uma elevada capacidade de tamponamento do meio.

A DQO inicial na tabela é a DQO total do efluente, enquanto a DQO final foi medida como solúvel, sem interferência de sólidos biológicos na análise para uma melhor avaliação do potencial de produção de metano em cada condição. Observa-se uma remoção de DQO de $95 \%$ a $98 \%$, no entanto, boa parte desta DQO não foi metabolizada a metano, podendo estar adsorvida ao lodo, pois a produção específica de metano (PEM) ainda é bem menor que o valor teórico (350 $\mathrm{mL} \mathrm{CH}_{4}(\mathrm{CNTP}) / \mathrm{g}$ DQO removida). 
Verifica-se que um melhor controle das condições de incubação no respirômetro, além da introdução de agitação intermitente, aumentaram consideravelmente a PEM em comparação aos valores obtidos em experimentos com frascos penicilina, em batelada e sem agitação (valores entre 94,1 e 199,6 mL $\mathrm{CH}_{4} / \mathrm{g}$ DQO removida, dados não mostrados). A diferença entre as condições foi reduzida com melhores resultados em termos de produção específica de metano na condição 5, com suplementação com $\mathrm{NH}_{4} \mathrm{Cl}$, fosfato e macronutrientes $\left(229,7 \mathrm{~mL} \mathrm{CH}_{4}(\mathrm{CNTP}) / \mathrm{g}\right.$ DQO removida), seguida da condição 3, com suplementação de $\mathrm{NH}_{4} \mathrm{Cl}$ e fosfato $(223,4 \mathrm{~mL}$ $\mathrm{CH}_{4}(\mathrm{CNTP}) / g$ DQO removida). A suplementação com uréia (condições 2 e 4) e soluções de macro e micronutrientes (condição 6) não fez muita diferença na produção de metano em comparação à condição Controle.

Tabela 3. Resumo dos resultados obtidos em termos de remoção de DQO e produção específica de metano para o efluente pré-tratado sob diferentes condições de suplementação.

\begin{tabular}{|c|c|c|c|c|c|c|}
\hline Condição & $\begin{array}{c}\text { DQO } \\
\text { inicial } \\
(\mathrm{mg} / \mathrm{L})\end{array}$ & $\begin{array}{c}\text { DQO } \\
\text { final } \\
(\mathrm{mg} / \mathrm{L})\end{array}$ & $\begin{array}{c}\mathrm{pH} \\
\text { final }\end{array}$ & $\begin{array}{l}\text { Remoção } \\
\text { DQO (\%) }\end{array}$ & $\begin{array}{c}\text { Volume } \\
\mathrm{CH}_{4} \\
\text { (CNTP) }\end{array}$ & $\begin{array}{l}\mathrm{PEM}\left(\mathrm{mL} \mathrm{CH}_{4} / \mathrm{g}\right. \\
\text { DQO removida) }\end{array}$ \\
\hline 1 & $2898 \pm 35$ & $128 \pm 32$ & $6,50 \pm 0,0$ & $95,1 \pm 1,2$ & $221,1 \pm 7,3$ & 216,9 \\
\hline 2 & $2515 \pm 76$ & $57 \pm 6$ & $7,0 \pm 0,0$ & $97,7 \pm 0,2$ & $190,8 \pm 1,0$ & 208,7 \\
\hline 3 & $2629 \pm 57$ & $54 \pm 8$ & $6,5 \pm 0,1$ & $97,9 \pm 0,3$ & $205,5 \pm 5,9$ & 223,4 \\
\hline 4 & $2516 \pm 109$ & $64 \pm 3$ & $7,0 \pm 0,0$ & $97,5 \pm 0,2$ & $192,6 \pm 0,7$ & 213,5 \\
\hline 5 & $2583 \pm 6$ & $73 \pm 7$ & $6,7 \pm 0,1$ & $97,2 \pm 0,5$ & $206,6 \pm 3,5$ & 229,7 \\
\hline 6 & $2951 \pm 35$ & $116 \pm 6$ & $6,5 \pm 0,0$ & $96,1 \pm 0,2$ & $220,5 \pm 7,0$ & 220,8 \\
\hline
\end{tabular}

$\mathrm{pH}$ inicial $=7,0$, DQO inicial $=3000 \mathrm{mg} / \mathrm{L}$.

A produção de metano nos ensaios com DQO inicial de 12000 mg/L e lodo não adaptado a adaptado foi monitorada até 8 dias, sendo os resultados obtidos apresentados na Figura 1 e Tabela 4. Conforme o esperado, os lodos adaptados apresentaram maior PEM que os lodos novos, comprovando que a adaptação pode gerar resultados mais promissores em termos de metano. Ao se comparar a PEM nas condições 1 e 5 com lodo novo e DQO inicial $3000 \mathrm{mg} / \mathrm{L}$ (Tabela 3) com os dados da Tabela 4 (com DQO inicial $12.000 \mathrm{mg} / \mathrm{L}$ ), a PEM aumenta cerca de $17 \%$ na condição 5 e $14 \%$ na condição 1 , com maior DQO inicial. Portanto, não houve inibição pelo substrato.

Com base nos resultados obtidos, decidiu-se por selecionar a condição 5 para a partida de um reator de bancada e reduzir gradualmente a suplementação ao longo da operação do mesmo. 


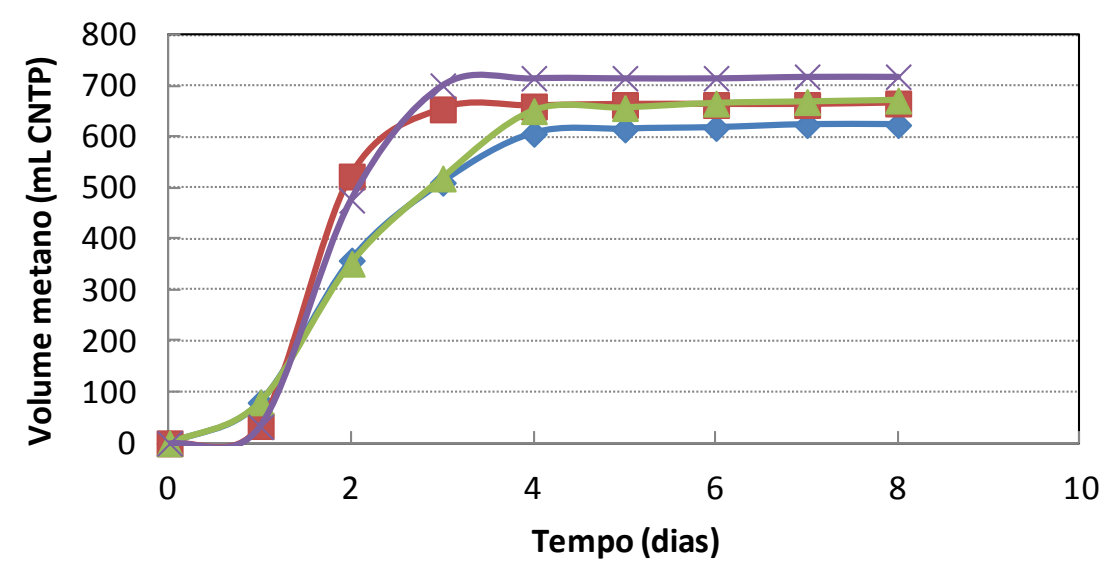

$\longrightarrow$ Condição 1 - lodo novo $\quad-$ Condição 1 - lodo adaptado
$\leftarrow$ Condição 5 - lodo novo $\quad *$ Condição 5 - lodo adaptado

Figura 1. Evolução da produção de biogás $\left(30^{\circ} \mathrm{C}\right)$ do efluente pré-tratado sem (condição 1) e com suplementação com $\mathrm{NH}_{4} \mathrm{Cl}, \mathrm{KH}_{2} \mathrm{PO}_{4}$ e solução de micronutrientes $1 \mathrm{~mL} / \mathrm{L}$ (condição 5) em respirômetro com DQO inicial de $12000 \mathrm{mg} / \mathrm{L}$ com lodo novo e adaptado.

Tabela 4. Resumo dos resultados obtidos em termos de remoção de DQO e produção específica de metano para o efluente pré-tratado sob diferentes condições de suplementação com lodo novo e adaptado.

\begin{tabular}{|c|c|c|c|c|c|c|}
\hline Condição & $\begin{array}{c}\text { DQO } \\
\text { inicial } \\
(\mathrm{mg} / \mathrm{L})\end{array}$ & $\begin{array}{c}\mathrm{DQO} \\
\text { final } \\
(\mathrm{mg} / \mathrm{L}) \\
\end{array}$ & $\begin{array}{l}\mathrm{pH} \\
\text { final }\end{array}$ & $\begin{array}{l}\text { Remoção } \\
\text { DQO (\%) }\end{array}$ & $\begin{array}{c}\text { Volume } \\
\mathrm{CH}_{4} \\
(\mathrm{CNTP})\end{array}$ & $\begin{array}{l}\text { PEM }\left(\mathrm{mLCH}_{4} / \mathrm{g}\right. \\
\text { DQO removida) }\end{array}$ \\
\hline $1 \mathrm{LN}$ & 11340 & $94 \pm 12$ & $6,4 \pm 0,0$ & $99,2 \pm 0,1$ & $623,2 \pm 14,0$ & 246,8 \\
\hline $1 \mathrm{LA}$ & 12318 & $346 \pm 169$ & $6,9 \pm 0,0$ & $97,2 \pm 1,4$ & $665,5 \pm 5,1$ & 252,7 \\
\hline $5 \mathrm{LN}$ & 10856 & $108 \pm 7$ & $6,4 \pm 0,0$ & $99,0 \pm 0,1$ & $671,2 \pm 21,1$ & 268,8 \\
\hline $5 \mathrm{LA}$ & 11461 & $357 \pm 137$ & $6,9 \pm 0,0$ & $96,9 \pm 1,2$ & $717,9 \pm 11,0$ & 278,9 \\
\hline
\end{tabular}

$\mathrm{pH}$ inicial $=7,00 \pm 0,02$. LN = lodo novo (não adaptado), $\mathrm{LA}=$ lodo adaptado.

\section{CONCLUSÃO}

Os testes de biodegradabilidade anaeróbia em respirômetro mostraram que o efluente da indústria do biodiesel, quando em contato com lodo adaptado e suplementado com soluções contendo micronutrientes, nitrogênio e fósforo, apresenta uma alta eficiência na degradação de matéria orgânica - acima de $95 \%$ - e produção específica de metano - 278,9 $\mathrm{mL} \mathrm{CH}_{4} / \mathrm{g}$ DQO removida.

Os estudos apontam que o aumento gradativo da DQO inicial possibilitará uma melhor adaptação das bactérias anaeróbias e, com isso, o aumento da remoção de DQO com menor quantidade de suplementação, visando a aplicação deste tratamento nas indústrias produtoras deste biocombustível. 


\section{REFERÊNCIAS}

AGÊNCIA NACIONAL DO PETRÓLEO, GÁS NATURAL E BIOCOMBUSTÍVEIS. Biocombustíveis. Disponível em: $<\mathrm{http}: / / \mathrm{www} \cdot$ anp.gov.br/?pg=60467\&m=\&t1=\&t2=\&t3=\&t4=\&ar=\&ps=\&cachebust=138046014323 6>. Acessado em: 28/09/2013.

APHA, Standard Methods for the Examination of Water and Wastewater (Eds: L.S. Clesceri, A.E. Greenberg, A.D. Eaton, E.W. Rice), American Public Health Association, American Water Works Association and Water Environment Federation, Washington DC, 2005.

ARAÚJO, A.B.L. Tratamento do efluente da produção de biodiesel a partir do rejeito de óleo de fritura. Dissertação (Mestrado em Tecnologia de Processos Químicos e Bioquímicos) Escola de Química, Universidade Federal do Rio de Janeiro, Rio de Janeiro, 89 p., 2011.

CHERNICHARO, C. A. L. Reatores Anaeróbios. Princípios do Tratamento Biológico de Águas Residuárias. Edição Revisada e Ampliada. Departamento de Engenharia Sanitária e Ambiental, Universidade Federal de Minas Gerais (UFMG), Belo Horizonte, MG, 379 p., 2007.

CONSELHO NACIONAL DE POLÍTICA ENERGÉTICA (BRASIL). Resolução CNPE: Resolução vigente publicada em 23 de outubro de 2009. Ministério de Minas e Energia. 16 p., 2009.

DABDOUB, M.J.; BRONZEL, J.I.; RAMPIN, M.A. Biodiesel: visão crítica do status atual e perspectivas na academia e na indústria. Química Nova v. 32, n. 3, p. 776-792, 2009.

MENESES, J.M.; VASCONCELOS, R.F.; FERNANDES, T.F.; ARAÚJO, G.T. Tratamento do efluente do biodiesel utilizando a eletrocoagulação/flotação: investigação dos parâmetros operacionais. Química Nova v. 35, n. 2, p.235-240. 2012.

PALOMINO-ROMERO, J.A.; LEITE, O.M.; EGUILUZ, K.I.B.; SALAZAR-BANDA, G.R.; SILVA, D.P.; CAVALCANTI, E.B. Tratamento dos efluentes gerados na produção de biodiesel. Química Nova v. 35, n. 2, p. 367-378. 2012.

SEBRAE - SERVIÇO BRASILEIRO DE APOIO ÀS MICRO E PEQUENAS EMPRESAS. Cartilha de Biodiesel. Brasília, Distrito Federal, 65p., 2007.

SUEHARA, K.; KAWAMOTO, Y.; FUJII, E.; KOHDA, J.; NAKANO, Y.; YANO, T. Biological treatment of wastewater discharged from biodiesel fuel production plant with alkali-catalyzed transesterification. Journal of Bioscience and Bioengineering. v. 100, n. 4, p. 437-442, 2005. 